\title{
LA RESOLUCIÓN JUDICIAL FIRME Y EL PROCESO CONSTITUCIONAL DE AMPARO
}

The finAl JUdicIAL RESOLUTION AND tHE CONSTITUTIONAL PROCESS OF AMPARO

Alexander Orihuela Abregú* Universidad Peruana Los Andes

Recepción: 16/10/2017

Aceptación: 20/11/2017

\section{Resumen}

Tratándose del proceso de amparo contra resoluciones judiciales, un tema que resulta controversial es la determinación de la firmeza de la resolución judicial que será objeto de la garantía constitucional. Mediante el análisis jurisprudencial, el autor da cuenta respecto a cuándo se adquiere tal calidad a efectos de lograr el presupuesto para el ejercicio de la aludida garantía.

Palabras clave: Resolución judicial firme; proceso de amparo; tutela jurisdiccional efectiva; debido proceso.

\section{Abstract}

In the case of amparo proceedings against judicial resolutions, a controversial issue is the determination of the resoluteness' of the judicial decision to be the subject of the constitutional guarantee. Based on the jurisprudential analysis, the author shows when this quality should be acquired to achieving the resources for the exercise of the guarantee.

Keywords: Final judicial resolution; amparo process; effective judicial protection; due process.

Magistrado en la Sala Civil Permanente en la Corte Superior de Justicia de Junín. Profesor en la Universidad Peruana Los Andes. 


\section{A MODO DE INTRODUCCIÓN}

Conforme a lo regulado por el Código Procesal Constitucional, nuestro sistema jurídico ha adoptado una posición permisiva para el cuestionamiento de las resoluciones judiciales mediante el proceso constitucional de amparo, esto es, siempre que las mismas se hayan dictado con manifiesto agravio de la tutela procesal efectiva y que comprenda el derecho a la tutela jurisdiccional, así como el principio del debido proceso en general, debiendo además ser materia del cuestionamiento - necesariamente— sólo las resoluciones que hayan adquirido firmeza.

Por tanto, ya que existen muchos aspectos discutibles, el tema de «la firmeza de la resolución» es uno de los aspectos que genera mayor controversia y desencuentros entre quienes nos hallamos inmiscuidos en el sistema de impartición de justicia, sea desde la posición de las partes interesadas o como representantes del Estado. Ello, en razón a que, al ser un aspecto pasible de verificación al momento de calificación de la demanda, genera en muchos casos la improcedencia liminar de la misma.

Por esta razón, pretendemos formar una posición al respecto, tomando en cuenta además la postura del Tribunal Constitucional.

\section{EL PROCESO CONSTITUCIONAL DE AMPARO}

El artículo segundo del Título Preliminar del Código Procesal Constitucional establece que los fines esenciales de los procesos constitucionales son garantizar la primacía de la Constitución y la vigencia efectiva de los derechos constitucionales, por ello el efecto de las decisiones estimatorias que se obtienen en estos procesos, sobre todo en aquellos ligados a la libertad, es el de reponer las cosas al estado anterior al de la violación o amenaza de violación de un derecho constitucional.

\section{ALCANCES}

Por regla, este proceso se utiliza con la finalidad de proteger los denominados derechos de la libertad, distintos a la libertad personal [protegida por el proceso de habeas corpus] y aquellos que no son protegidos por la acción de cumplimiento, la cual tiene una finalidad específica: ordenar al funcionario o autoridad pública renuente para que dé cumplimiento a una norma 
legal o ejecute un acto administrativo firme o se pronuncie expresamente cuando las normas legales le ordenan emitir una resolución administrativa o dictar un reglamento, si fuera el caso.

Así también, su ámbito de protección es distinto al que abarca el proceso de habeas data, que más bien protege los derechos constitucionales reconocidos por los incisos 5 y 6 del artículo 2 de la Constitución, empero, generalmente la demanda estará dirigida contra cualquier funcionario, autoridad o persona. Sin embargo, de manera excepcional también se permite que la demanda se dirija contra una resolución emitida por un juez, entendiéndose que esta providencia se ha emitido dentro de un proceso judicial en el cual las partes comprendidas han ejercido de manera regular sus derechos procesales pertinentes.

El artículo 4 del Código Procesal Constitucional indica que «[e]l amparo procede respecto de resoluciones judiciales firmes dictadas con manifiesto agravio a la tutela procesal efectiva, que comprende el acceso a la justicia y el debido proceso. Es improcedente cuando el agraviado dejó consentir la resolución que dice afectarlo». Ahora bien, actualmente el tema de la "permisibilidad o no para cuestionar resoluciones judiciales» es ya un tema pacífico, aun cuando existen sectores de la doctrina que consideran que las resoluciones judiciales no deben ser cuestionadas mediante el proceso constitucional, sobre todo cuando la decisión judicial es una que ha puesto fin al proceso judicial, puesto que, mientras las resoluciones judiciales puedan ser cuestionadas dentro del proceso ordinario, no será posible recurrir a la vía constitucional.

$\mathrm{Al}$ margen de los varios requisitos establecidos por ley para la viabilización del proceso de amparo contra una resolución judicial, uno de los aspectos que también causan controversia, y que además es utilizado por los jueces para declarar la improcedencia liminar de una demanda, es la no verificación de la calidad de «FIRME» que debe tener la resolución judicial que se pretende judicializar, bajo el argumento de que la misma contiene un agravio a la tutela procesal efectiva, que a su vez comprende el acceso a la justicia y el debido proceso. En este caso, lo que corresponde es determinar las características o situaciones que nos permitan tener la certeza de que nos hallamos frente a una resolución judicial firme y que como tal será admitida la demanda de amparo contra ella, para que de este modo el juez constitucional declare la nulidad de la decisión, acto o resolución que 
hayan impedido el pleno ejercicio de los derechos constitucionales protegidos del accionante, con la consecuente determinación de sus efectos.

\section{RESOLUCIÓN JUDICIAL FIRME}

Nuestra legislación procesal no se refiere propiamente a las resoluciones firmes, sino a las resoluciones que han adquirido la autoridad de cosa juzgada, entendiéndose como aquella resolución que adquirió firmeza y que como tal no puede ser objeto de nuevo pronunciamiento judicial, correspondiendo ordenar su ejecución o cumplimiento conforme al artículo 123 del Código Procesal Civil, el mismo que refiere lo siguiente: «[u] na resolución adquiere la autoridad de cosa juzgada cuando: 1. No proceden contra ella otros medios impugnatorios que los ya resueltos o, 2 . Las partes renuncian expresamente a interponer medios impugnatorios o dejan transcurrir los plazos sin formularlos...». Y, en el caso del proceso de amparo, la disposición legal antes referida sólo precisa las resoluciones judiciales firmes.

Si pretendiéramos entender como resolución judicial firme aquella que adquirió la autoridad de cosa juzgada, tendríamos que aceptar también que mediante el proceso constitucional de amparo se pueden cuestionar todas las resoluciones finales, incluyendo aquellas que adquirieron dicha calidad, incluso por no haber sido impugnadas dentro del proceso ordinario en el que se emitieron. Sin embargo, esto resulta incompatible con lo establecido en el Código Procesal Constitucional, pues el aludido artículo 4 establece que es improcedente el proceso de amparo, cuando el agraviado -entiéndase demandante en el proceso de amparo- dejó consentir la resolución que dice afectarlo. Lo que nos lleva a la simple conclusión de que sólo podrán ser judicializadas vía proceso de amparo las resoluciones judiciales que, habiendo sido emitidas dentro del proceso, hayan sido impugnadas por quien se considere agraviado por la misma, lo que a su vez nos lleva a concluir que no siempre una resolución firme es sinónimo de resolución con autoridad de cosa juzgada, ya que la resolución firme será una resolución con la autoridad de cosa juzgada, pero que adquirió dicha calidad luego de haber sido necesariamente impugnada. Lo que finalmente significa que las resoluciones judiciales que adquieren la autoridad de cosa juzgada sin haber sido impugnadas en la forma que establece la ley, no podrán ser cuestionadas mediante el proceso constitucional de amparo. 
En este primer punto — referente a la calidad de firme de la resolución- de algún modo queda claro, pues ha sido — cuando menos, mayoritariamenteasumido pacíficamente. No obstante, pueden surgir otros problemas en la calificación de la demanda, como es el caso de cuándo considerar que la resolución que se cuestiona ha sido impugnada o si es suficiente que la parte procesal interponga el recurso, sin importar si el mismo es denegado o admitido. Entonces, si al calificar la demanda comprobamos que existen resoluciones de las instancias superiores con un pronunciamiento sobre el fondo de la materia, no habrá ningún problema para admitirla, empero el problema surgirá cuando existan decisiones de la instancia judicial que declaren la improcedencia de la demanda por haber sido presentada de manera extemporánea o cuando habiéndose concedido el recurso, la instancia superior la vuelve a calificar y declara improcedente el mismo o la instancia superior emite una sentencia inhibitoria.

\section{IMPROCEDENCIA DEL RECURSO EXTEMPORÁNEO}

Cuando la parte procesal interpone el recurso de apelación y lo hace de manera extemporánea, resulta conforme a ley que el juez de la causa declare su improcedencia, pudiendo la parte afectada utilizar el recurso de queja para que se verifique si la denegatoria fue dispuesta conforme a ley o no. Ahora, si la instancia superior no la estima, la improcedencia es definitiva o firme, significa que no existe impugnación y, como tal, una eventual demanda de amparo contra resolución judicial en ese proceso también será desestimada liminarmente por no haberse configurado el requisito de la resolución judicial firme.

\section{CALIFICACIÓN DEL RECURSO POR EL SUPERIOR}

Tratándose de un proceso de naturaleza penal, el juez superior puede realizar una nueva calificación del recurso concedido, esto, conforme a lo establecido por el artículo 405 del Código Procesal Penal, el cual refiere que «[e]l Juez que deba conocer la impugnación, aún de oficio, podrá controlar la admisibilidad del recurso y, en su caso, podrá anular el concesorio»; tal como ha ocurrido en el Expediente N. ${ }^{\circ}$ 501-2017-1-1501-JR-PE-01, el mismo que indica que

[...] para la calificación positiva del recurso de apelación esta debe cumplir de manera copulativa con los requisitos establecidos en el artículo $405.1^{\circ}$ del 
Código Procesal Penal [...] expresiones que no constituyen propiamente una pretensión, sino una consecuencia lógica de su apelación [...] siendo así, al no cumplir con las exigencias de orden procedimental debe rechazar de plano el recurso de apelación [...] DEClARAR NUlo (sic) la resolución [...], mediante el cual el Segundo Juzgado Unipersonal de Huancayo concede la apelación.

Por lo que consideramos que en el caso referido en la resolución citada tampoco se cumple con el requisito de la existencia de una resolución firme, que permita cuestionar la resolución judicial que dicho proceso contenía la decisión por la que hallaban penalmente responsable al procesado.

En el caso de los procesos civiles, el juez superior — como juez de revisión o de apelación - también está facultado para volver a calificar el recurso concedido por el juez de origen o de la causa, esto es, en concordancia con el artículo 367 del Código Procesal Civil, el mismo que prescribe que «[e]l superior también puede declarar inadmisible o improcedente la apelación, si advierte que no se han cumplido los requisitos para su concesorio. En este caso, además declarará nulo el concesorio». En tal sentido, a pesar de que el juez de primera instancia haya concedido el recurso, no existirá apelación, porque así lo dispone el juez superior, conforme a la disposición legal precitada, lo que significa también que en ese supuesto tampoco existirá la resolución firme que se requiere para recurrir a la vía del amparo.

Consideramos, a su vez, que debe aplicarse el mismo criterio para el caso en el que el juez de revisión emita una sentencia de vista de naturaleza inhibitoria, conforme a lo señalado en la última parte del artículo 121 del Código Procesal Civil.

El análisis que hemos realizado para asumir la posición plasmada en el presente trabajo puede ser corroborado con la interpretación que hace el Tribunal Constitucional en algunas de sus resoluciones, como aquella providencia recaída en el Expediente N. ${ }^{\circ}$ 960-2012 PHC/TC, del 20 de abril del 2012, en la que precisa

[e]ste Tribunal ha señalado en la sentencia recaída en el Expediente 41072004-HC/TC (caso Lionel Richie Villar De la Cruz) que debe entenderse como resolución judicial firme aquella contra la que se ha agotado los recursos previstos por la ley procesal de la materia, lo que supone el agotamiento de los recursos antes de la interposición de la demanda [...] en el proceso que se le siguió por el delito contra la libertad sexual-violación en agravio de menor de 14 años (Expediente No. 00361-2004-0-1608), interpuso recurso de nulidad, el cual se tuvo por no interpuesto al no cumplir con ser fundamentado en el plazo [...]. Por ende, al no configurarse el requisito de procedibilidad exigido 
por la norma procesal constitucional, corresponde la aplicación, a contrario sensu, del artículo $4^{\circ}$ del Código Procesal Constitucional.

Al ser la máxima instancia de interpretación de la Constitución la que ha establecido que si un recurso de apelación, concedido por la instancia de origen, ha sido nulificado por la instancia superior — declarando nulo el concesorio- extingue el recurso, convirtiendo la apelada en una resolución consentida y, como tal, ya no reviste la calidad de resolución firme, que le podría permitir a las partes interponer una demanda de amparo contra la resolución judicial.

Por último, pueden notarse voces aisladas que consideren que si bien es cierto existe un pronunciamiento del Tribunal Constitucional sobre este tema, al no tratarse de un precedente vinculante, no existe la obligación de aplicarlo ni de compartir el criterio. Empero, nuestra postura es diferente, toda vez que el artículo VI del Título Preliminar del Código Procesal Constitucional precisa que "[l] os Jueces interpretan y aplican las leyes o toda norma con rango de ley y los reglamentos según sus preceptos y principios constitucionales, conforme a la interpretación de los mismos que resulte de las resoluciones dictadas por el Tribunal Constitucional». Consecuentemente, considerando que el juzgador no cuenta con argumentos lo suficientemente contundentes para rebatir el criterio establecido por el Tribunal Constitucional, la interpretación que se realice será conforme a la del Tribunal Constitucional, debe tenerse presente que la justicia se imparte por y para los hombres dentro de un sistema democrático, en el que la discrecionalidad del juez se halla limitada por la razonabilidad y los argumentos plausibles. 